\title{
Bidirectional selection on threshold size for flowering in Cynoglossum officinale (hound's- tongue)
}

\author{
RENATE A. WESSELINGH* \& TOM J. DE JONG \\ Institute of Evolutionary and Ecological Sciences, Leiden University, P. O. Box 9516, NL-2300 RA Leiden, \\ The Netherlands
}

\begin{abstract}
Previous studies have demonstrated that many facultative biennials show variation in threshold size for flowering. In order to quantify the genetic variation for this character, we performed a two-way artificial selection experiment on threshold size in Cynoglossum officinale. The parental generation, established from seed from a natural population, showed large variation in threshold sizes (2.6-13.4 g). After one generation of selection for low threshold sizes all plants in the $F_{1}$ flowered at sizes below $3.2 \mathrm{~g}$. In the high selection line none of the $F_{1}$ plants under $3.6 \mathrm{~g}$ flowered, and there were very large nonflowering plants (up to $17.2 \mathrm{~g}$ ). By interpreting the logistic regression of flowering probability on plant size as a cumulative frequency distribution of threshold sizes, we could derive the frequency distributions of threshold sizes in each generation. These were used to estimate the narrow-sense heritabilities by the standard procedure for artificial selection on a quantitative character. This gave 'heritabilities' of 0.35 and 0.32 for the high and low selection lines, respectively. A previously constructed optimization model, applied to the population in our study area, predicted strong selection against low threshold sizes, but a fairly equal fitness for threshold sizes around and above the optimum. This flat fitness profile may explain why the natural population of Cynoglossum officinale harbours extensive genetic variation for this character.
\end{abstract}

Keywords: artificial selection, facultative biennial, heritability, life history, monocarpy, threshold size for flowering.

\section{Introduction}

Facultative biennial plants have a typical life history. They flower only once, like annual plants, but they can live vegetatively for several years before they finally flower and die. Most facultative biennial species can flower only after exposure to cold (vernalization), followed by a long-day photoperiod. A size requirement has to be met, a 'threshold size', before a plant can react to cold or long days, the inductive stimuli (Werner, 1975). Plants can have a threshold size for vernalization, for photo-induction, or both. The threshold size acts as a yardstick. At the time flowering can be induced - in winter by vernalization or in spring by photo-induction - the actual size of the plant is compared with the internal threshold size setting: if it is larger, the plant will be induced to flower, if not, it will spend another season as a vegetative plant.

Many studies have shown that the probability of flowering in a population does not switch suddenly, but

*Correspondence. increases gradually with size (van der Meijden \& van der Waals-Kooi, 1979; Gross, 1981; Reinartz, 1984; Lacey, 1988; Klinkhamer et al., 1991). The fact that the observations did not show the same threshold size for all plants within a population has been explained in various ways. First, if we measure the plant before or long after its reproductive status for the next season has been set, variation can occur because of differential growth between the moment of status determination and the measurements (Baskin \& Baskin, 1979). Secondly, other factors than size may influence the decision. In Daucus carota, for instance, the relative growth rate of an individual plant at the end of the summer is negatively correlated with its flowering probability in the next season (Lacey, 1986). Evenly sized plants can thus differ in reproductive status because of differences in growth rate. Thirdly, the correlation between the size measure and the actual internal factor controlling flowering might not be perfect (de Jong et al., 1986). But even when measurements are made at the right moment, and there is no influence of other factors, the variation within a 
population is maintained in experiments under controlled conditions, as shown for Cynoglossum officinale (Wesselingh et al., 1993). If the variation arises solely from an imperfect size estimate, one would find equal amounts of variation for each population with this kind of experiment. But different populations of $C$. officinale show different levels of variation, ranging from no variation at all to a broad range of transition between 0 and 100 per cent flowering. The last explanation is that the variation observed has a genetic basis.

Lacey (1986) studied the genetic control of flowering in Daucus carota by collecting seeds from plants with different generation times from a garden plot. The offspring were grown in a controlled environment with simulated seasons in temperature and daylength. The phenotype of the maternal plant - annual, biennial or triennial - was reflected in the offspring's flowering behaviour. The group of annual mothers had the highest frequency of annual offspring, and triennial mothers produced the most longer-lived plants. The occurrence of annual plants points to variation in vernalization requirement. Because Lacey did not measure the sizes of the maternal plants, it is not possible to say if the correspondence of year of flowering between the biennial and triennial mothers and their offspring is the result of a genetically determined threshold size. It could result from differences in cold requirement as well: triennial mothers and their offspring may need more than one vernalization period before they are able to flower.

Threshold size for flowering has a profound impact on plant life history (Kachi \& Hirose, 1985; Klinkhamer et al., 1987a; de Jong et al., 1989). In unproductive habitats, where biennial species are most abundant, plants will usually not attain a size beyond their threshold size within one season. Cynoglossum officinale occurs naturally in sand dunes. In our study area, Meijendel, 88 per cent of the plants in a cohort delayed flowering beyond their third year (de Jong et al., 1986), and ages over 5 years are not uncommon (pers. obs.). A high threshold size will result in a long vegetative period of several years. When the plant finally surpasses its threshold size, it will be large, and thus produce many seeds. However, the chances of dying before the reproductive stage has been reached can be considerable. Plants with a low threshold size have the advantage of a short generation time, but their seed production will be low. Delay of flowering for another year is profitable as long as the expected increase in seed production by further plant growth compensates for the risk of death in that year (de Jong et al., 1987). Thus both size-dependent survival and size-dependent growth will influence the optimal threshold size. Habitats with high rosette survival and good growing opportunities for large rosettes favour high threshold sizes. Knowledge of the amount of genetic variation present is indispensable for understanding and predicting the response to selection processes.

The aim of this paper is to investigate whether threshold size for flowering in $C$. officinale reacts to selection. This facultative biennial species has an absolute vernalization requirement: without a cold treatment it will never flower (de Jong et al., 1986). If a plant has attained a size larger than its threshold size after the growing season, the formation of flower primordia starts during winter. Circumstances during (T. J. de Jong, unpublished data) and after the cold period (de Jong et al., 1986) do not affect the flowering probability. The threshold size for flowering is in fact a threshold size for vernalization: plants will not react to cold unless large enough. This relatively simple mechanism makes the species a suitable object for experiments. An artificial selection experiment was performed to see if the threshold sizes of parents and offspring are correlated, and how variation is distributed within and among offspring groups. We used the estimated total dry weight of the plant as a size measure.

Threshold size is predicted to be a quantitative trait, influenced by several genes (Falconer, 1989). It is a difficult character for genetic analysis, as it cannot be measured on an individual plant. If a plant flowers, its size before winter was larger than its threshold size. If, on the other hand, it retains its vegetative state, the actual plant size was below its threshold size. The threshold size for a genotype can only be pinpointed by cloning the plant and growing the cloned individuals to a range of sizes. If each genotype is represented by a single plant, threshold size behaves like a threshold character (Falconer, 1989), although it is not truly one. Therefore, we could not estimate a heritability sensu stricto, but under some assumptions we were able to use general methods to estimate the relative importance of genetic components, analogous to the calculations for narrow-sense heritability (Falconer, 1989).

\section{Methods}

\section{Study species}

Cynoglossum officinale L. (Boraginaceae) is a facultative biennial species of open, disturbed sites such as sand dunes and range lands (de Jong et al., 1990). It is self-compatible, and pollinated by bumble bees and honey bees. Six weeks of exposure to $5^{\circ} \mathrm{C}$ is sufficient to vernalize a plant under laboratory conditions, 
provided that it is large enough. Primordial flowers become visible in cross-sections made during the cold period (de Jong et al., 1986). For the development of the flowering stem the plant needs to be exposed to a long-day photoperiod. We have studied this species for more than 10 years in the sand dunes of Meijendel, along the North Sea coast. Here $C$. officinale grows in abundance. The area has a patchy combination of habitat types: bare sand, mosses and herbs, single bushes and poplar thickets. Cynoglossum officinale grows in all habitats, except in dense thickets. Phenotypic differences in threshold size between local populations in the open areas and in poplar thickets have been found (R. A. Wesselingh, in prep.).

\section{General outline of the selection experiment}

In this section we give only the outline of the experiment. Experimental details are given in the next sections.

The artificial selection experiment comprised one generation of selection. For the parental $\langle\mathrm{P}\rangle$ generation, seeds were collected in the natural population in the Meijendel area, and plants were grown in a climate chamber (Fig. 1). We obtained differently sized plants by varying the number of days they were allowed to grow before exposure to an artificial cold period. After this 'winter' plants were returned to the growth room, and we recorded whether or not they flowered. The smallest flowering plants were chosen to be the parents of the low line. The largest vegetative plants were allowed to grow further and were then exposed to a second cold period. All had surpassed their threshold size in this second growing 'season' and flowered subsequently. These were the parents of the high line. To compare the two selection lines with the parental generation we used seeds from the same seed batch as the $\mathrm{P}$ generation was taken from, and grew the plants together with the $F_{1} s$. The $F_{1} s$ and the repeated $P$ generation were grown under the same conditions as the parental plants, and after a cold period the flowering response was scored in the same way.

As size estimate we used root crown diameter (RCD). This measure correlates well with plant dry weight just before winter (de Jong et al., 1986), because the above-ground parts die back, and only the tap root remains.

\section{Parental generation}

At six sites in Meijendel we collected seeds of 40 plants in August 1990. Three sites were in poplar thickets
Fig. 1 Diagram of the relationships between the plants used in the artificial selection experiment on Cynoglossum officinale. Arrows represent seeds, a box depicts a generation of plants. At the top of the figure are the six sites in Meijendel from which seeds were taken in August 1990. The field plants have been numbered from 1 to 240 , and offspring are characterized by the maternal number plus a suffix. The seeds from the field were used in the $\mathrm{P}$ generation, the large, central rectangle. The two selected groups are at the extreme ends. The bottom row shows the three groups in the second stage, the repeated $P$ group (left) and both $F_{1} s$ (right). field sites

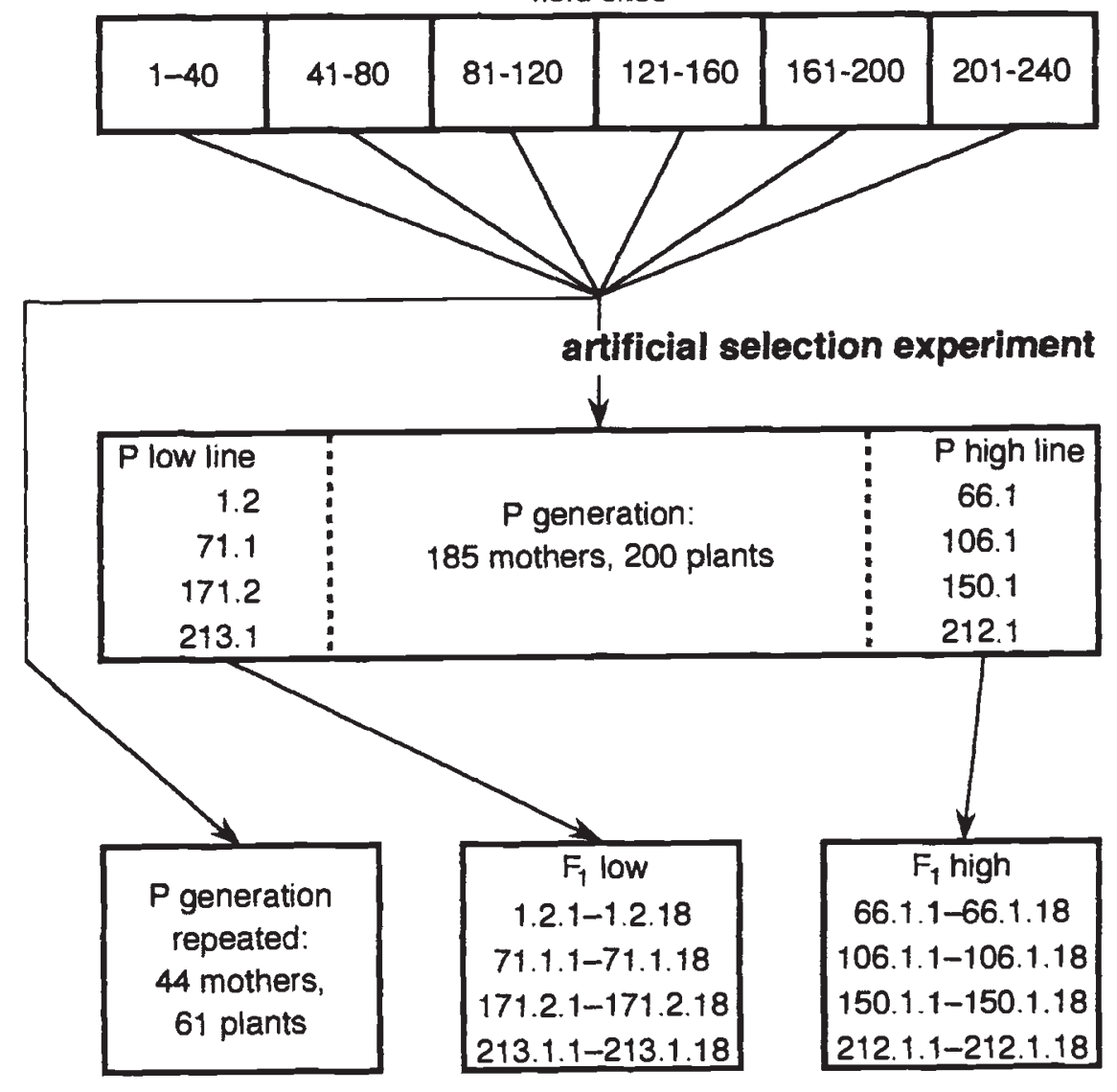


(1-120), and three in open areas (121-240). The seeds were stored air-dry and dark at room temperature. For each maternal plant eight seeds were put in petri dishes on moist filter paper. The seed coat was slightly cut to break seed dormancy. The seeds were incubated at $20^{\circ} \mathrm{C} / 10^{\circ} \mathrm{C}$ with a $16 \mathrm{~h}$ light period for 2 weeks. Not all seeds germinated; the number of plants with no germinating seeds varied between one and ten per site, 43 in total. To have equal numbers of mother plants for each site ( 39 or 40 ), we used 230 seedlings from 185 different mothers, with a maximum of two plants per mother. Each seedling was planted in a container (diameter $18 \mathrm{~cm}$, volume $3 \mathrm{~L}$ ) with a mixture of dune sand and 5 per cent compost. The plants were grown in a climate chamber with fluorescent light $\left(52 \mathrm{Wm}^{-2}, 16\right.$ $\mathrm{h}$ photoperiod), $20^{\circ} \mathrm{C}$ at day and $10^{\circ} \mathrm{C}$ at night, at 70 per cent relative humidity. From the second week onwards they received Steiner nutrient solution, increasing from $75 \mathrm{~mL}$ to $225 \mathrm{~mL}$ in week 4 and later. The length of the growing period for individual plants ranged from 31 to 86 days, after which each plant was measured and transferred to a cold room. Thirty plants were harvested, all from mothers that were represented by two offspring. The roots of these plants were collected by gently washing out the sand. Root and shoot were dried separately at $70^{\circ} \mathrm{C}$ for at least $48 \mathrm{~h}$ and weighed to the nearest $\mathrm{mg}$. RCD (in $\mathrm{mm}$ ) was closely correlated to plant dry weight (DW): DW $(\mathrm{g})=0.0111 \times \mathrm{RCD}^{2.9944}(n=30, r=0.924)$. We only measured RCD on the plants harvested, not on those in the experiment. Initially we aimed to obtain five size classes on the basis of total leaf length (leaf length summed over all leaves), and this was the original criterion to transfer plants to the cold. But at the analysis of the harvest data it turned out that total leaf length was a poor estimate of plant dry weight. We therefore discarded this measure and used age (in days) instead. This correlated very well with total plant dry weight (DW, in $\mathrm{g}$ ), because the seedlings were all similar in size and in good condition, and equally aged plants will not have had very different weights: $\mathrm{DW}=4.0204$ $\times 10^{-4} \times$ age $^{2.4449}(n=30, r=0.959)$.

After 10 weeks in the cold room $\left(5^{\circ} \mathrm{C}\right.$, daylength 8 h), plants were returned to the same growth room $\left(20^{\circ} \mathrm{C} / 12^{\circ} \mathrm{C}, 18 \mathrm{~h}\right.$ photoperiod). Each plant received $300 \mathrm{~mL}$ nutrient solution per week, starting in the second week after its return to the growth room. Each plant was checked for signs of flower stalk development at least three times a week. We recorded whether or not a plant flowered, as well as the date of the opening of the first flower. The plants that did not show signs of flowering after 100 days in the growth room were considered vegetative. At that time seed-set had started in all flowering plants.
We found no genetic differences in threshold size between the plants from the two habitat types $(R$. A. Wesselingh, in preparation), and decided to take all plants together to form the parental generation for the selection experiment.

\section{$F_{1}$ generation}

To obtain an $F_{1}$ in the low line we intercrossed the five flowering plants in the $\mathrm{P}$ generation that had the lowest DW before the cold treatment, by probing flowers with a fine brush, switching to another plant after each flower. No attempt was made to prevent self-pollination, and the degree of selfing in the $F_{1}$ is unknown. The $F_{1}$ in the high line was established by taking the five plants with the highest DW before the cold treatment that did not show any sign of flowering 15 weeks after their return to the growth room. These plants received a second 10 -week cold period, after which they all flowered: their dry weights before the second cold treatment were approximately $50-80 \mathrm{~g}$, high enough to surpass any reasonable threshold size. Again plants were cross-pollinated by hand. In both lines only four of the five plants yielded enough seeds, and, therefore, the $F_{1}$ in both lines consisted of the offspring of four mothers and five fathers. From each maternal group we grew 20 plants, of which two were harvested. We intended to repeat the $P$ generation with seed from 72 mothers, but because of loss of seed viability we could only use seed from 44 mothers. As it is unlikely that seed viability is correlated with threshold size for flowering, these plants form a random sample from the parental generation. Three mothers of the parents of the low line $(71,171,213)$ and two of the high line $(106,212)$ were represented in the repeated $P$ group $\left(\mathbf{P}_{\mathrm{r}}\right)$. It consisted of 67 plants, again with a maximum of two plants per mother. The $F_{1}$ and $P_{r}$ were grown in the same growth room under the same conditions before, during, and after the cold treatment as the parental plants. Because the growth room plants had produced heavier seeds than those from the wild population $\left(\mathbf{P}_{\mathrm{r}}\right)$, the resulting starting weights for the seedlings also differed. We therefore could not use age anymore as a measure of the total plant dry weight, and we used root crown diameter (RCD) instead. The RCD was measured (precision $0.1 \mathrm{~mm}$ ) with callipers on the plants in situ before they went to the cold room. This gave the following equation: $\mathrm{DW}$ $(\mathrm{g})=0.0355 \times \mathrm{RCD}^{2.4807}(n=19, r=0.892)$.

\section{Data analysis}

To describe the relationship between plant size and flowering probability and to test for differences between groups we used the following logistic 
equation:

$p=\frac{1}{1+\mathrm{e}^{\mu+\alpha x}}$,

where $x$ is plant size (estimated dry weight in $g$ ), and $p$ is the fraction flowering. $\mu$ and $\alpha$ are the parameters that determine the shape of this sigmoid curve, estimated by maximum likelihood analysis (Klinkhamer et al., 1987b). From this analysis the test statistic $\Lambda$ is derived, which can be used to test if curves differ significantly. $\Lambda$ is appoximately $\chi^{2}$-distributed. Both the interpretation of the parameters of the logistic equation and the maximum-likelihood analysis are described in detail in Wesselingh et al. (1993).

\section{Simulation of sample size effects}

The $\mathrm{P}$ generation consisted of 200 plants, but in the repeated $\mathrm{P}$ group only 61 plants were used. To check what effects this difference in group size had on the results, we simulated this situation numerically. We chose a size range $(S: 0-20 \mathrm{~g})$ and a threshold size range ( $T$ : normal distribution with mean $8 \mathrm{~g}$ and $\sigma 3 \mathrm{~g}$, truncated beyond $2 \sigma$ ). From these ranges we drew a size and a threshold size at random, and obtained in this way either a 'flowering' $(S>T)$ or a 'vegetative' $(S<T)$ plant. This was repeated 200 times. From this sample of 200 plants we determined the transition range, the size of the largest 'vegetative' minus that of the smallest 'flowering' plant. This was also performed for a random subset of 61 plants, and this transition range was expressed as a percentage of the transition range of the whole group. We repeated the procedure 200 times, and calculated the frequency distribution of the percentages.

\section{Results}

\section{Parental generation}

The $\mathrm{P}$ generation showed considerable variation in threshold sizes. The smallest plants that flowered had an estimated dry weight of $2.57 \mathrm{~g}$; the largest nonflowering plant weighed $13.04 \mathrm{~g}$. The width of this transition range from 0 to 100 per cent flowering comprised 53 per cent of the total weight range studied (Table 1, Fig. 2). The low selection line was established from the offspring of the five smallest plants that flowered, with an average dry weight of $2.64 \mathrm{~g}$ (range 2.57-2.74 g). The five largest plants that remained vegetative, the parents of $F_{1}$ high, had an average weight of $10.30 \mathrm{~g}$ (8.95-13.04 g) just before their first cold period.
Table 1 Characteristics of the four groups of Cynoglossum officinale in the artificial selection experiment. The number of plants in each group and the dry weight range within each group are given. The width of the transition range is the size difference between the smallest flowering and the largest vegetative plant. The smallest flowering plant has the lowest threshold size observed, and the largest vegetative plant the highest threshold size observed. The width of the transition range is, therefore, a measure of the amount of variation in threshold sizes present in a group

\begin{tabular}{lrrrrr}
\hline & & \multicolumn{3}{c}{ Transition range } \\
\cline { 4 - 7 } Group & $n$ & $\begin{array}{c}\text { DW range } \\
(\mathrm{g})\end{array}$ & $\begin{array}{c}\text { Smallest } \\
\text { flowering }\end{array}$ & $\begin{array}{c}\text { Largest } \\
\text { vegetative }\end{array}$ & $\begin{array}{c}\text { Range } \\
(\mathrm{g})\end{array}$ \\
\hline P & 200 & $1.78-21.57$ & 2.57 & 13.04 & 10.47 \\
P repeated & 61 & $0.20-22.61$ & 2.44 & 6.76 & 4.32 \\
F $_{1}$ low & 70 & $0.38-34.46$ & 1.56 & 3.15 & 1.59 \\
$\mathrm{~F}_{1}$ high & 70 & $0.20-27.69$ & 3.55 & 17.23 & 13.68 \\
\hline
\end{tabular}

\section{P repeated}

An obvious difference between the $\mathrm{P}$ generation and the $P_{r}$ group is that the transition range in the former is much wider: the largest nonflowering plant in $\dot{P}_{r}$ is only half as heavy as the largest vegetative $P$ plant (Table 1, Fig. 2). This difference is likely to be caused by the differences in sample size between the two groups. Plants with exceptionally high threshold sizes were probably not represented in $P_{r}$ by chance, because of variation within the offspring groups of the maternal field parents and the smaller sample size in $\mathrm{P}_{\mathrm{r}}$. We simulated this sampling effect, and the transition range width of the smaller sample was on average 57 per cent of that of the large group. In 29 per cent of the cases it was equal to or smaller than 41.3 per cent, the observed percentage. The sampling effect alone is strong enough to explain the difference in variation between $\mathrm{P}$ and $\mathrm{P}_{\mathrm{r}}$.

\section{$F$, low and $F$, high}

The two $F_{1} s$ and $P_{r}$ are distinctly and significantly different from each other with respect to threshold size (Fig. 2, Table 2). The curve for the low selection line has shifted towards lower threshold sizes, compared to the other curves. The midpoint weight - where the logistic equation predicts 50 per cent flowering - is much lower than in any of the other groups, and $F_{1}$ low shows a steep increase in flowering probability with size. In three of the four maternal groups within this line no within-group variation in threshold size could be detected (Table 3). The smallest flowering plant of 


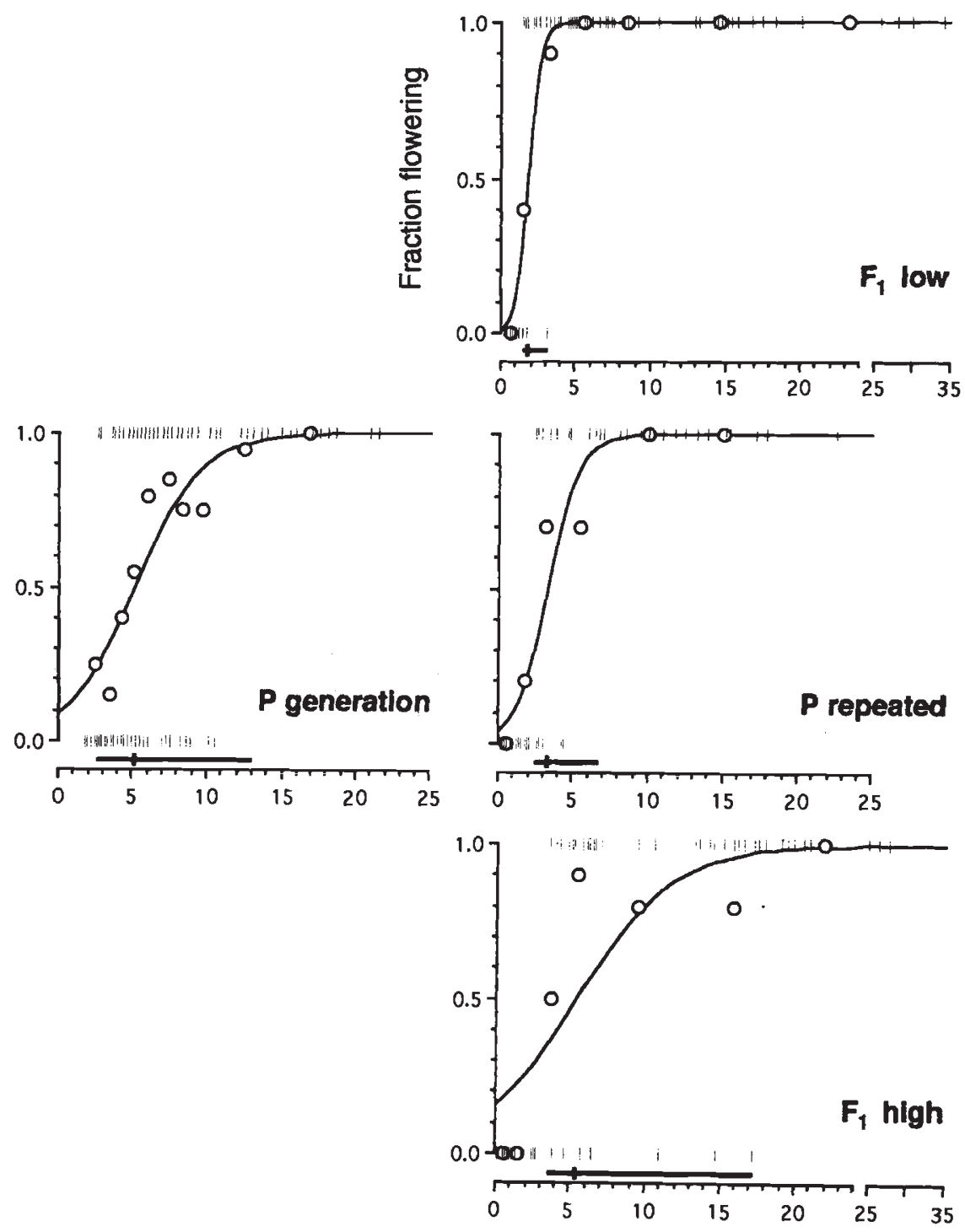

Plant dry weight $(\mathrm{g})$
Fig. 2 The relationships between plant size and flowering probability for the artificial selection experiment on Cynoglossum officinale. On the left is the $\mathrm{P}$ generation, on the right the two $F_{1}$ groups and $\mathrm{P}_{\mathrm{r}}$. The curves are the logistic equations, with parameters $\mu$ and $\alpha$ as denoted in Table 2 . The vertical dashes are the individual data points, at flowering probability zero for vegetative and at unity for flowering plants. The circles represent the average weight of at least 10 plants (for the $P$ generation 20 ), sorted by increasing size, and the fraction flowering in such a subgroup. The bold line along the horizontal axis represents the transition range (Table 1); the vertical notch is the midpoint weight (Table 2).
Table 2 Results of the maximum likelihood analysis for the artificial selection experiment on Cynoglossum officinale. The midpoint weight is the dry weight at which the logistic equation predicts 50 per cent flowering. The last section gives the test results for differences between curves; above the diagonal the values for $\Lambda$; below, the $P$-values

\begin{tabular}{|c|c|c|c|c|c|c|c|}
\hline \multirow[b]{3}{*}{ Group } & \multicolumn{4}{|c|}{ Maximum-likelihood estimates } & \multirow{2}{*}{\multicolumn{3}{|c|}{$P \backslash \Lambda$}} \\
\hline & & & & & & & \\
\hline & $\ln \left(\mathbf{L}_{\max }\right)$ & $\mu$ & $\alpha$ & weight $(\mathrm{g})$ & $P_{r}$ & $\mathrm{~F}_{1}$ low & $F_{1}$ high \\
\hline $\mathbf{P}$ & -96.307 & 2.300 & -0.449 & 5.12 & & & \\
\hline$P$ repeated & -17.605 & 3.208 & -0.972 & 3.30 & - & 10.185 & 9.547 \\
\hline $\mathrm{F}_{1}$ low & -9.101 & 4.772 & -2.579 & 1.85 & 0.0062 & - & 30.242 \\
\hline$F_{1}$ high & -30.727 & 1.688 & -0.312 & 5.41 & 0.0085 & 0.0001 & - \\
\hline
\end{tabular}


Table 3 The transition ranges for the four maternal sib groups in each of the two selection lines of Cynoglossum officinale. Given are the estimated dry weights ( $\mathrm{g}$ ) of the smallest flowering and the largest vegetative plant in each group, and the width of the transition range $(\mathrm{g})$. The last column contains the scores $(0=$ vegetative, $1=$ flowering) of the individual plants around the transition range sorted by increasing size. To the left of the first dash all plants are vegetative, and to the right of the second dash all plants flowered. In between the two dashes is the transition range: the leftmost digit (1) represents the smallest flowering plant, the zero at the end the largest vegetative plant. For the families with a zero transition range, the smallest flowering and the largest vegetative plant are outside the dashes

\begin{tabular}{rcccl}
\hline $\begin{array}{l}\text { Maternal } \\
\text { families }\end{array}$ & $\begin{array}{c}\text { Smallest } \\
\text { flowering }\end{array}$ & $\begin{array}{c}\text { Largest } \\
\text { vegetative }\end{array}$ & $\begin{array}{c}\text { Width } \\
(\mathrm{g})\end{array}$ & $\begin{array}{c}\text { Distribution within } \\
\text { transition range }\end{array}$ \\
\hline F low & & & & \\
1.2 & 1.65 & 1.11 & 0 & $0--1$ \\
71.1 & 3.28 & 1.74 & 0 & $0--1$ \\
171.2 & 1.56 & 3.15 & 1.59 & $0-1110-1$ \\
213.1 & 1.83 & 1.48 & 0 & $0--1$ \\
$\mathrm{~F}_{1}$ high & & & & \\
66.1 & 3.98 & 1.32 & 0 & $0--1$ \\
106.1 & 3.98 & 6.37 & 2.39 & $0-1010-1$ \\
150.1 & 3.98 & 14.86 & 10.88 & $0-101010-1$ \\
212.1 & 3.55 & 17.23 & 13.68 & $0-101111110-1$ \\
\hline
\end{tabular}

the $F_{1}$ was found in the low line, and its largest nonflowering plant still had a lower weight than the smallest flowering plant in the $F_{1}$ high. This means that the transition ranges of both lines do not overlap. The high line has the highest midpoint weight, higher than in any other group. It also has a much wider transition range: in three of the four groups very large vegetative plants occurred (Table 3) while other somewhat smaller plants in these groups did flower. This occasional appearance causes the logistic equation to fit less well, because the flowering probability for very large plants does not approach unity. The differences between the equations are all highly significant, though (Table 2).

\section{The relative contribution of genetic components to threshold size}

Use of the logistic regression equations that describe the relationship between plant size and flowering probability (Table 2) gives some quantitative insight into the strength of the response. At $3 \mathrm{~g}$ dry weight the flowering probabilities for each of the three groups are 0.427 for $P_{r}, 0.951$ for $F_{1}$ low and 0.320 for $F_{1}$ high. Thus one generation of selection for low threshold sizes more than doubled the flowering probability for 3 $\mathrm{g}$ plants. The probability estimate for $F_{1}$ high is too high, because the - symmetrical - curve is forced downwards at large sizes by the very large vegetative plants, and thus upwards at sizes below the midpoint weight. In fact, no plants below $3.5 \mathrm{~g}$ flowered in this group, so the flowering probability for $3 \mathrm{~g}$ plants is very likely to be close to zero.

To obtain an estimate of the relative contribution of genetic components to threshold size we applied the method for calculation of a realized heritability for quantitative traits. The usual way to obtain the realized heritability $h^{2}$ from a selection experiment involves calculating the selection differential $S$ and the response $R ; h^{2}=R / S$ (Falconer, 1989). $S$ can be calculated by assuming that the character is normally distributed, and that selection is by truncation. The logistic equation that is fitted to the plant size-flowering response data can be interpreted as a cumulative frequency function of the threshold sizes present in a group of plants. For example, a fraction flowering of 0.50 at $5.12 \mathrm{~g}$ dry weight indicates that in a group of plants with that size, half has a threshold size smaller than $5.12 \mathrm{~g}$, and the cumulative frequency of threshold sizes at that size would be 50 per cent. The graphical representation of the derivative of the logistic function, the frequency distribution of the threshold sizes, is a bell-shaped curve with the top at the midpoint weight (Fig. 3). It is not a normal distribution - its tails are longer - but the deviation is small. We approximated the standard deviation $\sigma_{\mathrm{P}}$ of the distribution in the $\mathrm{P}$ generation by calculating the 0.25 quartile, which was $2.68 \mathrm{~g}$ dry 

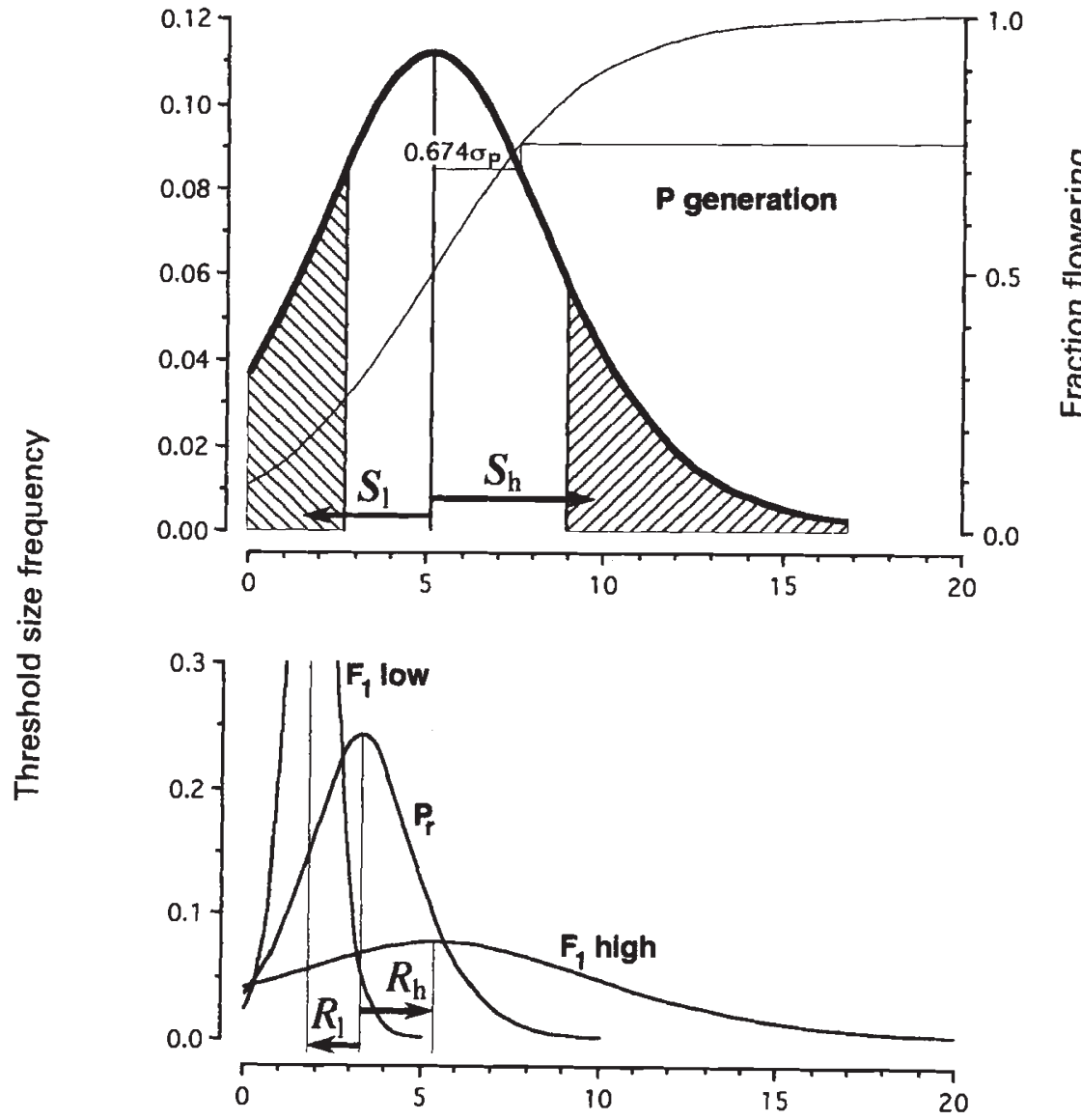

Plant dry weight (g)
Fig. 3 Graphical representation of the 'heritability' calculation. In the top figure both the logistic equation for plant size-flowering probability in the $\mathrm{P}$ generation (thin line, right ordinate) and its derivative, the frequency distribution of threshold sizes (bold line, left ordinate) are drawn. The hatched areas under the curve indicate the fractions selected for low $(\mathbb{\mathbb { N }})$ and high $(\mathbb{})$ threshold sizes. Although not drawn, the area to the left of the origin is also included in the proportion selected. $S_{1}$ and $S_{\mathrm{h}}$ are the two selection differentials. The bottom graph shows the threshold size frequency distributions for each of the $F_{1} s$, together with the frequency distribution for the repeated $P$ group $\left(P_{r}\right)$. The top of each frequency distribution lies at the midpoint weight (Table 2), $R_{1}$ and $R_{\mathrm{h}}$ are the responses to selection. Note that the ordinates of the graphs differ in scale. See text for further explanation. weight. In a normal distribution this fraction is reached at $0.674 \sigma$ from the mean, thus $\sigma_{\mathrm{P}}$ is estimated as $(5.12-2.68) / 0.674=3.63$, where 5.12 is the midpoint weight in the $\mathrm{P}$ generation (Table 2). We took the size of the largest parental plant in the $F_{1}$ low as the truncation value for the low line $(2.74 \mathrm{~g})$, and the size of the smallest parent in the $F_{1}$ high for the high line $(8.95 \mathrm{~g})$. In this way all threshold sizes selected for were in one of the truncated tails of the distribution. The intensity of selection $i$ is calculated from the percentage of the population selected. This is 25.5 per cent for the low line and 12.2 per cent for the high line - calculated by entering the truncation value in the logistic regression - and the intensities are 1.26 and 1.66 , respectively (Falconer, 1989: Appendix A). $S=i \sigma_{\mathrm{p}}$, thus the selection differentials are 4.57 for the low line and 6.02 for the high line. The response $R$ is the difference between the means of the generations before and after selection. We chose to compare the midpoint weights of the $F_{1} \mathrm{~S}$ with that of $\mathrm{P}_{r}$, because these groups were all grown simultaneously. The response for the low line is 1.45 , for the high line 2.11 . This results in heritability estimates of $R / S=0.32$ for $\mathrm{F}_{1}$ low and 0.35 for $\mathrm{F}_{1}$ high.

\section{Discussion}

\section{$F_{1}$ low versus $F_{1}$ high}

It is clear from the artificial selection experiment that there is a significant heritable component to threshold size for vernalization in $C$. officinale. Selection for low threshold sizes yields a strong response. High threshold sizes do not occur in the $F_{1}$ low, the variation in threshold sizes is reduced, and the lowest threshold sizes found in this group are well below $2 \mathrm{~g}$. Selection for high threshold sizes results in a dual response: both the minimum threshold size and the incidence of very large vegetative plants increases. This is a result of the way in which this line was selected. Since it is not possible to choose from flowering plants exactly those with a high threshold size, we selected the ones that did not flower at a large size, and brought 
them to flower. This is a form of 'negative' selection, in contrast to the 'positive' selection for the low threshold sizes. In the case of positive selection a plant has to score 'positive' at all - biochemical - steps of the flower induction process. The plants chosen by negative selection may, however, differ in the step that scores 'negative', although they all show the same response, namely nonflowering. Thus not only a high threshold size, but also other internal factors that influence the flowering response are in this way selected. It seems as though the two are in a way associated: offspring groups in which exceptionally large vegetative plants occur also have a high minimum threshold size $(>3.5 \mathrm{~g})$. Strict selection for high threshold sizes alone requires knowledge of the relation plant size-flowering probability for individual plants. This can only be accomplished by cloning.

\section{Consequences for the field situation}

Comparisons of the experimental data with field measurements are difficult, because of differences in plant habit. In the field, plants have no green leaves in winter, while in the laboratory experiments we included the leaves in the dry weight measurements. The roots are shaped differently if plants are grown in pots with ample water and nutrients, and root crown diameters are not comparable either. Midpoint weights in the field typically range from 1.7 to $5.2 \mathrm{~g}$, depending on season and habitat (Wesselingh et al., in preparation). It seems that the flowering weights in the growth room are somewhat above those found in the field.

From the optimization model of de Jong et al., (1989) it can be calculated on average how many years it would take for a plant to reach its threshold size. With a threshold size of $2 \mathrm{~g}$, the majority of plants flowers at the age of three to five. Only 1 per cent take 6 years before flowering. A threshold size of $5 \mathrm{~g}$ results in a shift of this flowering peak to 4-6 years (maximum 8 years). The same range is found for a threshold size of $10 \mathrm{~g}$, but here 1 per cent of the plants flower in their tenth year. The differences in threshold size between the two selection lines can have major effects on plant life history in the field situation.

\section{'Heritability'}

The 'heritability' for threshold size for flowering is $0.32-0.35$. Fifty per cent of the estimates of $h^{2}$ of life history traits exceed 0.2 , and about 10 per cent exceed 0.5 (Roff, 1992). A heritability in excess of 0.2 is moderate and more than sufficient to permit fairly rapid response to selection. For plants, heritabilities for fitness-associated traits are usually much lower, less than 0.3 (Platenkamp \& Shaw, 1992).
The results presented here suggest that although selection on threshold size for flowering can take place, it has not depleted the genetic variation for this character. There is a number of explanations of this phenomenon. First, selection in the wild does not act directly on threshold size itself, but on its immediate effects on fitness: generation time and seed production. For the latter, the actual size at flowering is crucial. Plant size just before the previous winter largely determines the size at flowering. This size can be just above the threshold size, but also much higher. When yearly rosette growth is slow, the difference between threshold size and actual size will be small. Only under favourable conditions will a plant 'overshoot' its threshold size very far with the size increment of one season. Thus the actual size at flowering is most closely linked to the threshold size when plants grow slowly, and selection will then be most effective.

A second explanation is provided by the optimization model presented earlier (de Jong et al., 1989). It predicts a flat fitness profile for sizes around the optimum threshold size, which was at $5 \mathrm{~g}$ dry weight. Fitness was low only for threshold sizes below $2 \mathrm{~g}$, but calculations did not go beyond $10 \mathrm{~g}$ dry weight. The existence of a wide range of near-optimal threshold sizes means that the selection process is very slow or absent for threshold sizes within this range.

A third explanation lies in the environmental heterogeneity. The study area consists of several habitat types. In the open areas survival and growth are generally low, except in wet summers (de Jong \& Klinkhamer, 1988). The poplar thickets provide moisture and a more nutrient-rich soil, but interspecific competition with other herbs is higher. The rainfall in summer is highly variable among years. Each year and each site could, therefore, yield a different fitness curve, and different selection pressures. Only when survival and growth are consistently different for several generations would a response to selection become visible. This means that the selection process would proceed fastest in areas with little environmental variation, and that the amount of genetic variation in a population may reflect the environmental variation. We think, however, that this shifting selective pressure is a less important factor in the maintenance of genetic variation than the shape of the fitness curve, because selection can be effective even in variable habitats. An example in which selection did result in differences in mean threshold size in two European populations of $C$. officinale is presented in Wesselingh et al. (1993). The Holkham population (England) has much higher threshold sizes than we find in Meijendel, and a forthcoming paper will show that these differences in threshold size can indeed be explained by differences in survival and growth between these populations. 


\section{Acknowledgements}

We thank Kirsten Wolff for her helpful comments and advise concerning the heritability calculations, and Peter Klinkhamer and Ed van der Meijden for their comments on the manuscript. Nicole van der Wel and Karin van der Veen-van Wijk gave technical assistance, and Evert Meelis provided statistical support.

\section{References}

BASKIN, J. M. AND BASKIN, c. c. 1979. Studies on the autecology and population biology of the weedy monocarpic perennial, Pastinaca sativa. J. Ecol., 67, 601-610.

DE JONG, T. J. AND KLINKHAMER, P. G. L. 1988. Population ecology of the biennials Cirsium vulgare and Cynoglossum officinale in a coastal sand-dune area. J. Ecol., 76, 366-382.

DE JONG, T. J., KLINKHAMER, P. G. L. AND PRINS, A. H. 1986. Flowering behaviour of the monocarpic perennial Cynoglossum officinale L. New Phytol., 103, 219-229.

DE JONG, T. J., KLINKHAMER, P. G. L. AND METZ, J. A. J. 1987. Selection for biennial life histories in plants. Vegetatio, 70, 149-156.

DE JONG, T. J., KLINKHAMER, P. G. L., GERITZ, S. A. H. AND VAN DER MEIJDEN, E. 1989. Why biennials delay flowering: an optimization model and field data on Cirsium vulgare and Cynoglossum officinale. Acta Bot. Neerl., 38, 41-55.

DE JONG, T. J., KLINKHAMER, P. G. L. AND BOORMAN, L. A. 1990. Biological Flora of the British Isles: Cynoglossum officinale L. J. Ecol., 78, 1123-1144.

FALCONER, D. S. 1989. Introduction to Quantitative Genetics, 3rd edn. Longman, London.

GROSS. K. L. 1981. Predictions of fate from rosette size in four 'biennial' plant species: Verbascum thapsus, Oenothera biennis, Daucus carota, and Tragopogon dubius. Oecologia, 48, 209-213.
KACHI, N. AND HIROSE, T. 1985. Population dynamics of Oenothera glazioviana in a sand-dune system with special reference to the adaptive significance of size-dependent reproduction. J. Ecol., 73, 887-901.

KLINKHAMER, P. G. L., DE JONG, T. J. AND MEELIS, E. 1987a. Lifehistory variation and the control of flowering in shortlived monocarps. Oikos, 49, 309-314.

KLINKHAMER, P. G. L., DE JONG, T. J. AND MEELIS, E. 1987b. Delay of flowering in the 'biennial' Cirsium vulgare: size effects and devernalization. Oikos, 49, 303-308.

KLINKHAMER, P. G. L., DE JONG, T. J. AND MEELIS, E. 1991. The control of flowering in the monocarpic perennial Carlina vulgaris. Oikos, 61, 88-95.

LACEY, E. P. 1986. The genetic and environmental control of reproductive timing in a short-lived monocarpic species Daucus carota (Umbelliferae). J. Ecol, , 74, 73-86.

LACEY, E. P. 1988. Latitudinal variation in reproductive timing of a short-lived monocarp, Daucus carota (Apiaceae). Ecology, 69, 220-232.

PLATENKAMP, G. A. J. AND SHAW, R. G. 1992. Environmental and genetic constraints on adaptive population differentiation in Anthoxanthum odoratum. Evolution, 46, 341-352.

REINARTZ, J. A. 1984. Life history variation of common mullein (Verbascum thapsus) I. Latitudinal differences in population dynamics and timing of reproduction. J. Ecol., 72, 897-912.

ROFF, D. A. 1992. The Evolution of Life Histories; Theory and Analysis. Chapman and Hall, New York.

VAN DER MEIJDEN, E. AND VAN DER WAALS-KooI, R. E. 1979. The population ecology of Senecio jacobaea in a sand dune system I. Reproductive strategy and the biennial habit. $J$. Ecol., 67, 131-153.

WERNER, P. A. 1975. Predictions of fate from rosette size in teasel (Dipsacus fullonum L.). Oecologia, 20, 197-201.

WESSELINGH, R. A., DE JONG, T. J., KLINKHAMER, P. G. L., VAN DIJK, M. J. AND SCHLATMANN, E. G. M. 1993. Geographical variation in threshold size for flowering in Cynoglossum officinale. Acta Bot. Neerl., 42, 81-91. 